\title{
ENTRE LA JOVEN POLONIA Y EL MODERNISMO HISPÁNICO: EL DR. JÓZEF LEONARD
}

ROBERTO MANSBERGER AMORÓS

Universidad Autónoma de Madrid

La particular situación histórica y cultural del Imperio Ruso en la segunda mitad del siglo XIX no sólo produjo la aparición de los grandes genios de la literatura rusa y polaca, sino también la de interesantes figuras secundarias, especialmente en el campo de la crítica y del ensayismo literario y filosofico y cuya función parece consistir en ejercer de difusores de la cultura eslava y de receptores de la europea occidental, de la que, a su vez, se muestran transmisores refinados. Tal es el caso de los polacos Józef Leonard y Teodoro de Wyzewa y del ruso Borís de Tannenberg. Los dos primeros, si bien separados por el espacio de una generación (Leonard nació en 1840 y Wyzewa en 1862), pertenecen a la en Polonia llamada etapa positivista, que incluye los movimientos y corrientes que suceden al Romanticismo desde la Insurrección de 1863 hasta 1914, entre los cuales la Joven Polonia (Mloda Polska) ocupa una significación paralela a la del Modernismo hispánico. Con el ruso Tannenberg, riguroso coetáneo de Wyzewa, están bajo el signo de lo francés y reciben la impronta cosmopolita de la Europa de fin de siglo y de un París donde el magisterio de Turgenev concentraba la presencia de lo eslavo. Algo separado de los anteriores, aunque dentro del grupo generacional de la Joven Polonia finisecular, habría que colocar la polifacética figura de Wincenty Lutoslawski, el longevo helenista y filosofo, cuyo viaje a España por los años ochenta en busca de materiales para su estudio sobre el pesimis- 
mo de fin de siglo le llevaría al círculo literario de Campoamor y a su matrimonio con Sofía Casanova, abriendo uno de los capítulos más interesantes de las relaciones literarias hispanopolacas'.

Una reflexion general sobre la cultura del siglo XIX basada en el valor ejemplificador de estas figuras nos llevarra a la hipótesis de que si trazásemos un arco de parábola entre la Joven Europa de 1830 a 1848 y la Europa Moderna de 1890 a 1905, nos encontrariamos, separadas por medio siglo, dos épocas bien diferenciadas pero que guardan entre sí una relación dialéctica de antítesis, relación que en la esfera de lo intelectual irfa del Romanticismo ilustrado al irracionalismo modernista; en la de lo moral, del optimismo al pesimismo; en la de lo cultural, de los nacionalismos al cosmopolitismo; en la de lo estético, del compromiso en el arte al «arte por el arte»; en la de lo político, de la revolución a la reacción, y, resumiéndolo todo, de la llamada Primavera de los Pueblos al Decadentismo. Es cierto que estos dos últimos conceptos son heterogéneos, pero ese mismo tránsito de lo ético a lo estético es una de las características más significativas de la cuestión. Y ciertamente también se trata de una simplificación que exigirfa toda clase de matizaciones, pero debemos pensar que no a mero azar se ha de atribuir el que los padres espirituales (por emplear la expresion tan querida de nuestro Clarín) del Fin de Siglo, los Renán, los Tolstoi, los Ruskin, los Baudelaire, los Wagner y los Marx, fueran todos ellos hombres de la generación de 1848, aquella que recogió los ideales de la Joven Europa y vivió su derrota.

Desde tal planteamiento, ninguna relación es más paradigmática que la de la primera Joven Polonia, nacionalista y romántica, con la segunda, modernista y cosmopolita (aunque de un cosmopolitismo nacionalista, si se me permite la paradoja). Permítaseme, también, recordar aquí algunos datos, a mi parecer, indispensables.

Cuando en 1898, Artur Górski, el escritor de orígenes positivistas y ribetes wagnerianos, publica en Zycie, la revista portavoz de la joven generación y cuyo director era, nada menos, que Przybyszewski, el jefe de fila del movimiento de kel arte por el arte» en Polonia, cuando Gorski publica, decimos, una serie de artículos bajo el común epígrafe de La Joven Polonia, su pluma está vuelta continuamente hacia la primera Joven Polonia, aquella que, anunciada en 1820 por la Oda a la juventud de Mickiewicz, culminaría con la Insurrección de Varsovia en

I W. Lutoslawski (1863-1954) cas6 con Soffa Casanova en 1887. El mismo afio se publico en Madrid por el Establecimiento tipografico de El Correo su opúsculo El personalismo: un nuevo sistema de filosofia. De regreso a Polonia recogerfa sus experiencias hispánicas en $\propto$ Wedrowki iberyskie» («Peregrinaciones ibéricas») dentro de la serie «Jak tanio podrózowak" ( barato»), Varsovia (¿1910?). V. Ofelia Luisa Alayeto, Sofla Casanova: a link between polish and spanish literatures (1862-1958). Tesis doctoral, City University of New York, 1983. 
la noche del 29 de noviembre de 1830 y desencadenarfa la destacada actividad revolucionaria, entre otros, de Lelewel, el historiador de Nowosilcov en Vilna, el refugiado amigo de Mazzini, el precursor de Marx en su teoría de la lucha de clases. Pero donde la conexión entre las dos generaciones homónimas, la de Lelewel y la de Gorski, se hace absolutamente patente es en el más ilustre de los representantes de la Joven Polonia finisecular: Stanislaw Wyspianski. Cuatro dramas suyos aparecidos entre 1898 y 1904 formando una especie de tetralogia del inmediato pasado nacional, La Varsoviana, Lelewel, La legión y La noche de noviembre, toman como motivo directo a la primera Joven Polonia. Se llega asi, cruzando el positivismo y el naturalismo, a enlazar los dos momentos claves de la historia de la Polonia moderna.

Es dentro de este marco donce hay que situar el eslavismo cosmopolita de Leonard, Wyzewa ${ }^{2}$ y Lutoslawski. De los tres, el primero, a la vez que nos ofrece unos perfiles menos conocidos que los otros dos, muestra ese enlace en Epocas y actitudes que presentamos como tesis en esta breve noticia biobibliográfica y es en él en quien fijaremos nuestra atención.

Su vida, que se extiende entre 1840 a 1908, tiene cuatro etapas marcadas por la insurrección antizarista de 1863 , en la que tomó parte, y cuyo aplastamiento le obligó a abandonar su Polonia natal: la etapa propiamente polaca, hasta la citada fecha; la europea, marcada por Paris; la española, centrada en Madrid; y la americana, que le lleva a diversas repúblicas centrales, con especial incidencia en Nicaragua, lo que reviste particular interés para una historia de la evolución de las letras hispanoamericanas. Nos ocuparemos en particular de estas dos últimas etapas, pues encontraremos, en la española, a un hijo de la primera Joven Polonia, y en la americana, a un adelantado del modemismo europeo del que participaba la segunda Joven Polonia.

De la etapa previa a su llegada a Madrid, tenemos referencias a traves de la breve nota biografica que nos transmite su amigo y correligionario español el poeta Ventura Ruiz Aguilera con motivo de la traducción al polaco que le hizo de su $\ll$ Balada de Polonia* y que va incluida en sus Ecos Nacionales y Cantares $^{3}$, dentro de la edición de 1873 de las Obras Completas, balada a que

2 Teodor de Wyzewa (o Wizewski), 1862-1917, hijo de un médico polaco establecido en Francia, es una de las figuras mís sugestivas de la crftica cosmopolita finisecular. Su labor como traductor del ruso es insoslayable en una investigación sobre la difusión de la literatura eslava en Francia y Occidente. Polifacetico ensayista y crítico, a el se debe la ola de wagnerismo que recorrió la Europa finisecular, sobre todo a través de su «Art wagnérien* (1885-86) recogido en Nos maitres, París, Perrin, 1895, y de la celebre Revue Wagnérienne (1885-1888).

${ }_{3}$ Madrid, Imprenca de la Biblioteca de Instrucción y Recreo. La «Balada* aparece en el libro segundo de $*$ Ecos nacionales* (pp. 174-176) y lleva la fecha de 1861. La traducción al polaco, firmada por J. Leonard, figura en las pp. 331-333. 
volveremos a referirnos. Dice el poeta, refiriéndose al traductor como «joven poeta... emigrado a consecuencia de la insurrección de 1863 y 64 ", que fue Leonard primer ayudante del general Kruk, que sucedio al dictador Langiewicz, y después comandante de escuadrón, habiendo publicado en su idioma nativo numerosos trabajos históricos y literarios, entre éstos Juan Ziska y los husitas, y una colección de opúsculos dedicados a los campesinos polacos, titulada Braterstwo (La fraternidad). «Actualmente - añade- es redactor de la Gaceta de Madrid, donde su ilustración y su profundo conocimiento de las principales lenguas vivas de Europa, son tan útiles como necesarios».

Cabe suponer que esa ilustración y ese conocimiento de lenguas le pondrfa en contacto con las nuevas corrientes literarias europeas, particularmente durante su estancia en París, y que en 1866 asistiría al nacimiento del Nouveau Parnasse francés, sospecha que conviene retener.

Leonard llego a Espana, en donde permanecería hasta 1881, en 1868; participo en la Revolución de Septiembre de aquel año $0^{4}$ en la cual creyo encontrar un paralelismo con la polaca de 1863; entro en relación con los círculos progresistas del país, pasando a formar parte de la interesante y hasta hoy poco estudiada colonia extranjera instalada en la capital, y formada, sobre todo, por centroeuropeos y eslavos, colonia que llevó a tener cierto peso específico en los medios culturales; baste citar, a modo de breve recordatorio, que en $\mathrm{Ma}$ drid residieron o pasaron más o menos largas temporadas personajes como Max Nordau, el hispanista Fastenrath, Alfred Löwy, el «tío madrileño de Kafka*; Bauer, el agente de Rotschidls; el citado Borfs de Tannenberg, que preparaba su Espagne Litteraire (1903); el bohemio y cosmopolita Bark, inmortalizado por Valle-Inclán en Luces de bohemia; el propio Lutoslaswski, en busca de materiales para su mencionado estudio sobre el pesimismo ${ }^{5}$ y su Kant en Espari $a^{6}$, y un largo etcetera, y que en Madrid se llegaron a publicar revistas internacionales como Les Matinées Espagnoles y la Spanich-Deutsche Revue. En tal contexto, Leonard hizo, en cierto modo, figura de precursor de ese cosmopolitismo finisecular que caracteriz6 a cierta parte de la España restauracionista frente al cerrado «casticismo» de la otra.

Protegido por personalidades de marcada proyección progresista en los años que precedieron a la Restauración, como Nemesio Fernández Cuesta (de

- Cfr. Clara E. Lida e Iris M. Zavala, La revolución de 1868; historia, pensamiento, literatura. New York, Las Américas Publishing Co., 1970.

s Pexymism, Varsovia, 1894.

- Publicado en los Kantstudien. 1896. En 1902 correría a cargo de Lutoslawski la parte relativa de la filosofia en Espana y Polonia en la Geschichie der Philosophie bajo la dirección de Ueberweg, edición Heinze. 
quien, por cierto, dicen las biografías que hablaba numerosos idiomas, entre ellos «eslavo»), Leonard, como nos informa Ruiz Aguilera en la nota referida, llegó a redactor jefe de la Gaceta de Madrid y colaboro en Las Novedades, portavoces del espíritu que sucedió al destronamiento de Isabel II. Ello le llevó a moverse en los ambientes krausistas, colaborando en las tareas docentes de la Institución Libre de Enseñanza, donde el 6 de mayo de 1878 pronunciaría una extensa conferencia sobre «Literatura Polaca y José Ignacio Kraszewski» ${ }^{7}$. La elección del gran poeta, historiador y patriota romántico como centro de su exposición, que, como no podfa ser menos, es una apasionada panorámica divulgativa de la historia y la literatura polacas desde sus origenes hasta la expatriación del ilustre prohombre, no es un capricho. Kraszewski había tomado parte en la «legendaria insurrección de 1830», como la llama Leonard, y, como él mismo, en la de 1863, lo que le obligó a emigrar a Alemania, de igual manera a como le sucedió a nuestro escritor. De modo que el autor de El último de los Siekierzyńskis (1851) constitufa a sus ojos un verdadero símbolo cuyos orígenes le conectaban con la primera Joven Polonia.

Pero donde la personalidad de Leonard adquiere particular interés para nosotros es en su amistad con el tantas veces citado Ruiz Aguilera. Poeta hoy relegado por la crítica a una discreta segunda fila, Ruiz Aguilera gozó, merecidamente, del aplauso de sus contemporáneos, Galdós entre otros, y, más tarde, hasta del mismo Rubén Dario:.

Pertenece Ventura Ruiz Aguilera a esa generación intermedia de españoles progresistas en la que figuraron hombres como Pi y Margall y Castelar. Atento a los sucesos de Europa, había publicado, con fuerte acento radical, la oda «En los últimos días de 1848* el mismo año revolucionario'. De igual tono es su «Europa de Noviembre de $1851 \%$, que lleva el expresivo subtítulo de «Recuerdo, a Kossuth» ${ }^{10}$. Diez años posterior es la en palabras de Galdós «admirable sobre toda ponderación», «Balada de Polonia»". Escrita con motivo de los sangrientos movimientos insurreccionales de 1861 , todo el poema gira en torno al martirologio de la nación polaca, que es presentada como «madre de bravos». Hacia el final de la composición el poeta se dirige a ella como

7 «Décimatercera conferencia (6 de marzo de 1878). Moderna literatura Polaca y Jose Ignacio Kraszewskiw. Madrid. Imprenta de la Institución Libre de Enseñanza, 1878.

- «La literatura en Centro Américas en Revista de Artes y Letras, 1888, artículo recogido por Raúl Silva Castro en Obras desconocidas de Rubén Darlo, Prensa de la Universidad de Chile, 1934, p. 199.

Op. cit., pp. 80-86.

10 Op. cit. pp. 242-243.

"V.N. 3. 
«Cristo de las naciones» y habla de su gloriosa resurrección. Asi, curiosamente, se aproxima al llamado «mesianismo polaco», una constante de la Weltanschauung en la Polonia moderna al decir de Lutoslawski ( ¡el mismo llegaria a creerse llamado a engendrar a ese redentor!) quien le dedicaría copiosas páginas en su «Polnische Philosophie» publicada en el Grundriss de Ueberweg ${ }^{12}$, mesianismo que el autor coloca al lado del catolicismo y del positivismo polacos del siglo XIX, centrándolo en la obra de Wronski, Mickiewicz, Towianski, Trentowski, Slowacki y otros románticos, hasta llegar a Norwid.

La «Balada de Polonia» afectaba y conmovio directamente a Leonard, quien se brind 6 a traducirla al polaco, y Ruiz Aguilera la inserto, entre otras versiones de sus poesías, al final de sus Ecos Nacionales y Cantares $^{13}$, añadiendo la nota biográfica que ya conocemos. Cimentada la amistad entre ambos escritores, Leonard volvería a traducir a su lengua nativa con el título de «Ból nad bóle», «El dolor de los dolores», de Elegias y armonias ${ }^{14}$, en el que el poeta español llora la muerte de su hija, aún nifia, y que, en opinión del profesor E.S. Urbafski, a quien debemos un autorizado artículo sobre el autor polaco en su etapa española ${ }^{15}$, recuerda los Trenos del clásico Kochanowski por su tono de honda desesperacion. Para los estudiosos de la traducción entre ambos idiomas no dejará, por cierto, de ser interesante observar la transcripción a que el traductor recurre en su deseo de reflejar la pronunciación polaca a partir de la ortografía española, transcripción que en sendas notas idénticas al pie de ambos textos se considera obligado a explicar.

La Restauración borbónica no le fue favorable al emigrado polaco. En 1881, después de una breve estancia en París de la que no tenemos noticia directa, lo encontramos en América Central. Aquí se abre uno de los capítulos más sugestivos de literatura comparada.

12 «Der polnische Messianismus» pp. 308-320 de ia V parte («Die Philosophie des Auslandes» del Grundriss der Geschichte der Philosophie, edicion de 1928. Berlín, E.S. Mittler und Sohn.

13 V. n. 3.

14 Citamos por la edición de 1873 de las Obras Completas, Madrid, Aribau y Ca. El texto original y la traducción (en prosa y sin firma) ocupan respectivamente las pp. 19-54 y 246-256.

Que la actividad traductora de Leonard no parb ahr, queda constancia en la nota a la página 246, que textualmente dice: «En el volumen que contiene los Ecos Nacionales y los Cantares, inserte la versión que el joven e ilustrado escritor polaco, $D$. José Leonard, habia tenido la bondad de hacer a su idioma de la Balada de Polonia. Hoy debo nuevamente mostrarle mi reconocimiento, no solo por la traducción de las cuatro Eleglas con que desde luego me habla brindado, sino por ia de otras muchas con que se ha servido favorecerme. (Op. cit. p. 318).

15 «Dr. Józef Leonard and his cultural-political activities in Spain between 1868 and 1881\%, The Polish Review, x11, 3, Summer, 1967, pp. 18-27. 
Prescindiré de la rica y múltiple actividad del Dr. Leonard en esta etapa final de su vida, que le llevaria al desempeño de numerosas misiones diplomáticas y pedagógicas por tierras americanas, y me centrart en su relación con el joven Rubén Darío en Nicaragua, y ello por las implicaciones que cabe suponer en la aparición del Modernismo hispánico finisecular.

Ya en la primera biografía del poeta, publicada en 1890 en el Diccionario Enciclopédico Hispano-Americano de la Casa Montaner y Simón de Barcelona, se lee: «En el Instituto de Occidente de dicha ciudad [León, de Nicaragua] [Darío] estudió humanidades bajo la inmediata dirección de hábiles catedráticos. Así, su profesor de literatura lo fue José Leonard, escritor polaco que emigró a España por causas políticas, en donde fue redactor de la Gaceta de Madrid; en seguida pasó a París y de allí a Nicaraguam. La relación entre Leonard y Darío fue, pues, la de maestro a discípulo y en tales términos aparece evocada en más de una ocasión por el autor de Azul... Precisamente del mismo año del célebre libro, 1888 , son dos preciosos testimonios del poeta en los que me detendré con cierta extensión. El primero en importancia es el publicado en la Revista de Artes y Letras, tomos XI y XII, formando parte de un extenso ensayo del autor sobre «La literatura en Centro América». Darío recuerda cómo al fundarse los institutos que hicieron las veces de la antigua Universidad de León en Nicaragua, todos los profesores eran extranjeros, ky casi todos -precisa- de fama, de ilustración reconocidas. De España, entre otros, llegaron un científico, el doctor Salvador Calderón, y un literato: Jose Leonard. Sobre él recoge, sin duda, las breves notas biográficas que nos transmite Ruiz Aguilera, a quien, el poeta cita, por cierto muy elogiosamente, como queda dicho, y del polaco subraya sus extraordinarias dotes para las lenguas, «como todos los de su raza» apostilla, y cómo fue en España kuno de los más ardientes luchadores en pro de la revolución filos6fica y social de los últimos tiempos». «Cuando el Gobierno que le protegía cayo - prosigue- Leonard tuvo que ir a París. Después de algún tiempo, aceptó el contrato para ir de profesor a Nicaragua, y llegó a allá (Darío escribe desde Santiago de Chile) acompañado del doctor Calderón». De la impronta dejada en el entonces jovencísimo poeta son las palabras que siguen y que cito en extracto:

«Por ciertas frases de reforma pronunciadas por Leonard en la inauguración del Instituto de Occidente, cierta parte de la sociedad de León, en un exceso de celo religioso, declaró la guerra a los nuevos profesores, a los que habían sido osados a decir por primera vez en pleno páblico la palabra libre pensamientow. El acoso de esta sociedad acab6 por producir la partida, al cabo de pocos años, primero de Calderón y luego de Leonard, que llegarfa a rector de la Universidad de Honduras, en Tegucigalpa, entre 1899 y 1902. Siguiendo su evocación, Darío concluye, despues 
de recordar que la nueva juventud de Nicaragua «les debe a ellos parte de lo que hoy sabex: \&Leonard hizo tomar un nuevo rumbo a los embriones de literatura nacional existente... Con sus lecciones form 6 las bases literarias de muchos de los que hoy ocupan el primer rango entre los que por allá escriben ${ }^{16}$. La declaración no puede ser más expresiva y no es mucho aventurar que el ilustre polaco, en sus estancias en París, de las que, como hemos visto, es dificil rastrear testimonios directos, tomarfa contacto con la revolución estética que se estaba produciendo e impregnaría a su joven discípulo de las esteticas parnasianas y simbolistas en boga, haciéndolo fecundo para la adopción de ese cosmopolitismo decadentista que es una de las características del gran poeta. De la indiscutida influencia francesa en la obra de Ruben Darío, entre otros, quedan estudios tan definitivos como el ya clásico de Mapes, donde, si bien brevemente, se cita el magisterio que ejerció Leonard sobre el poeta nicaragiense ${ }^{17}$.

El segundo testimonio rubendariano en aquel mismo año de 1888 sobre el ilustre emigrado, y con el que quisiera cerrar esta modesta aportación a este capítulo de la literatura comparada, son los recuerdos publicados por el poeta en La Libertad Electoral, de Santiago de Chile, en el número correspondiente al $1 .^{\circ}$ de marzo: se refieren a la evocación, llena de vivacidad, que Leonard le había hecho del célebre y prolífico folletinista español Manuel Fernández y González con quien se habła unido en amistad en su etapa madrileña. Ello da pie a Rubén Darío para referirse a su informador con los términos de «mi muy querido maestro y amigo don Jose Leonard y Bertholets ${ }^{18}$.

Son más las alusiones del poeta al «querido maestro» dispersas a lo largo de su obra hasta el final de su vida, pues en la Autobiografia de 1915 vuelve a dedicarle un amplio y encendido recuerdo y dice de él que «tuvo una vida novelesca y curiosam ${ }^{19}$.

Lo que a mí me interesa es sugerir cómo en la figura del emigrado polaco que fue Leonard se fragua un eslabón, y no el menor, que cierra el círculo que pasa por el eslavismo revolucionario de la primera Joven Polonia y el esteticismo cosmopolita y modernista del Fin de Siglo.

Madrid, noviembre de 1993.

16 V. n. 8 pp. 198-200.

17 Erwin K. Mapes, L'influence française dans l'oeuvre de Ruben Dario, París, Librerie Ancienne Honore Champion, 1925, p. 13.

is Artículo recogido en la edición de Silva Castro. V. supra.

19 Autobiografla, vol. XV de las Obras Completas, Madrid, Editorial «Mundo Latino», 1915, p. 33. 